\title{
Modelling the Restoration of Activity in a Biological Neural Network
}

\author{
Filipa Dos Santos \\ School of Computing and \\ Mathematics \\ Keele University \\ Newcastle-under-Lyme, UK \\ f.dos.santos@keele.ac.uk
}

\author{
Jannetta S Steyn \\ School of Computing Science \\ Newcastle University \\ Newcastle upon Tyne, UK \\ jannetta.steyn@newcastle.ac.uk
}

\author{
Peter Andras \\ School of Computing and \\ Mathematics \\ Keele University \\ Newcastle-under-Lyme, UK \\ p.andras@keele.ac.uk
}

\begin{abstract}
Understanding the mechanisms of restoration of activity in biological neural systems following exposure to damage is key for design of future neuro-prosthetic devices and restorative treatments. The pyloric rhythm network within the crustacean stomatogastric ganglion is a biological neural system that shows spontaneous restoration of activity following the stopping of inputs from higher control ganglia. We model the restoration of the activity in this network using conductancebased models of neurons and the alteration of conductance parameters of the model. Our analysis shows that this approach works only if some of the conductance values remain constrained following the stopping of higher inputs. Our model also shows that in order to model the restoration of the activity in this network it is not necessary to rely on complicated alterations of the mechanisms of Calcium ionic currents in the model, which was proposed previously.
\end{abstract}

Keywords-biological neural network; conductance-based model; neural activity restoration; stomatogastric ganglion

\section{INTRODUCTION}

Biological neurons and their networks are usually very complex and difficult to model. The activity of these neurons depends on the inputs they receive from other neurons, the neuromodulatory context to which they are exposed, and the previous activity of the neuron [1]. Models of neurons and neural networks based on simple mathematical abstractions (e.g. feedforward networks of sigmoidal neurons) capture the behaviour of their biological counterparts only in an abstract sense.

Physiologically realistic models of biological neurons and their networks can be built following the route of the HodgkinHuxley $(\mathrm{HH})$ models of neurons. These model the behaviour of the neuron using a set of differential equations that represent the dynamics of the activation and inactivation of ion channel molecules and of the membrane potential as a function of the modelled ionic currents [1]. While the HH approach is useful to produce realistic models of neurons, it is also difficult to use due to the large number of differential equations involved which compose typically a stiff equation system that requires careful numerical handling [2]. Alternatives are the use of simplified variants of the $\mathrm{HH}$ equations, such as the MorrisLecar, FitzHugh-Nagumo or Izhikevich model neurons, which give up, to some extent, the physiological realism in exchange for easier numerical handling of the model neurons $[3,4]$.

The restoration of activity in neural systems following damage is a major aim of applied neuroscience and neuroengineering research [5]. For this it is critically important to understand the underlying mechanisms of such spontaneous restorative process. An often researched neural system that shows spontaneous restoration of neural activity is the pyloric rhythm network within the crustacean stomatogastric ganglion (STG) [1]. Following the disconnection of the STG from higher controlling ganglia (e.g. by severing the single nerve that provides this connection) the rhythmic activity of the pyloric network stops, and then it recovers after $12-24$ hours $[1,6]$.

The recovery of rhythmic activity in the STG pyloric network has been modelled using HH models of STG neurons [6-9]. These models use some form of alteration of the mechanism of the Calcium ion currents in order to achieve the restarting of the rhythmic activity in the computational model of the STG [6-9].

Here we describe a model of the pyloric network of the STG using HH model neurons, including distinct models of each neuron belonging to classes of STG neurons with multiple copies (e.g. two pyloric dilator (PD) neurons). We model the impact of disconnection of the STG from higher ganglia and the restoration of the rhythmic activity of the pyloric network by modifying maximal conductance values of certain ionic currents. We show that this approach is successful and does not require the altering of the mechanisms of Calcium ion currents and also that its success depends on constraining the range of variation of some of the ionic current maximal conductances.

The rest of the paper is structured as follows. In the next section we briefly review the related works. Then we describe the computational model of the STG pyloric network that we used. This is followed by the presentation and analysis of our results. Finally the paper is closed by the discussion and conclusion section. 


\section{BACKGROUND}

\section{A. Conductance-based models of neurons}

A physiologically realistic modelling of neurons is based on the modelling of the dynamics of ionic currents and of the impact of this on the dynamics of the membrane potential of the neuron or parts of the neuron [1-4]. These models depend on parameters that represent the maximal conductance of ion channels corresponding to the modelled ionic currents and on further parameters that represent equilibrium potentials of ionic currents and others that determine the variation of the effective conductance of the ion channels by taking into account the dynamics of opening/closing and activation/inactivation probabilities of ion channels. The first such model was proposed by Hodgkin and Huxley in the 1950s [4]. The basic HH model takes into account the activity of a sodium, a potassium and a leak ionic current (see equation (1) below). Alternative versions of the model may include a variety of ionic currents (e.g. H-current, A-current, Calcium-dependent potassium current). The model may be applied to multiple compartments of a neuron (e.g. axon, soma, dendrites) with compartment-specific parameters. In addition to modelled ionic currents HH neuron models may include synaptic currents, gap junction currents, and inter-compartmental currents [6].

$$
C \cdot d V(t) / d t=-g_{K} m_{K}^{4}\left(V(t)-E_{K}\right)-g_{N a} m_{N a}{ }^{3} h_{N a}\left(V(t)-E_{N a}\right)
$$

$-g_{L}\left(V(t)-E_{L}\right)-I_{e x t}$

where $C$ is the capacitance of the membrane, $V(t)$ is the membrane potential difference, $g_{K}, g_{N a}$ and $g_{L}$ are the maximal conductances of the potassium, sodium and leak currents, $m_{K}$ and $m_{N a}$ are the activation probabilities of the corresponding channels and $h_{N a}$ is the inactivation probability of the sodium channels, $E_{K}, E_{N a}$ and $E_{L}$ are the equilibrium potentials of the corresponding currents, and $I_{\text {ext }}$ is an external current applied to the neuron (this may represent synaptic or gap junction currents or inter-compartmental currents). The opening and activation probabilities are determined according to equations of the following form

$$
d m_{K}(t) / d t=\left(m_{K, \text { inf }}(V)-m_{K}(t)\right) / \tau_{m, K}(V)
$$

where the inf and $\tau$ functions represent the voltage-dependent steady state and time constant functions and they are of the following form

$$
m_{K, \text { inf }}(V)=m_{K, \text { inf, min }}+\left(m_{K, \text { inf,max }}-m_{K, \text { inf,min }}\right) .
$$

$\left(1 /\left(1+\exp \left(m_{K, \text { inf }, \alpha} \cdot\left(V_{m, K, \text { inf,mid }}-V\right)\right)\right)\right.$

where $m_{K, \text { inf,min }}, \quad m_{K, \text { inf,max }}, \quad m_{K, \text { inf, } \alpha}$ and $V_{m, K, \text { inf,mid }}$ are set parameters of the equations. Similar equations apply to the $m_{N a}$ and $h_{N a}$ probabilities as well.
Given the many parameters and currents in the HH models of neurons, there are alternative, similar models as well, which reduce the number of parameters at the expense of also reducing the physiological realism of the models. Such alternative models are the Morris-Lecar, FitzHugh-Nagumo and the Izhikevich models [3,4].

The estimation of parameters for $\mathrm{HH}$ models is based on measurement of ion current specific conductance properties of biological neurons [6]. These measurements allow the estimation of the maximal conductance values and equilibrium potentials for the ionic currents and also the estimation of the parameters of the corresponding inf and $\tau$ functions. We note that values reported in the literature for maximal conductances and equilibrium potentials of various ionic currents are generally consistent, however the values reported for the parameters of the inf and $\tau$ functions are more variable $[6,10]$.

The parameter space for HH models of STG neurons has a complex structure, with many parts of the space having functionally equivalent corresponding model neurons [11]. The parameter space has been analysed by generating millions of model neurons and assessing their behaviour [11]. However the picking of the right parameter combinations for the modelling of a given STG neuron remains a problem in general - i.e. to pick parameters such that the model neurons behave realistically individually, when connected in a network, and also when exposed to changes in their neuromodulatory environment such as toxins or external stimulation [12].

It has been recognized that the maximal conductance values of certain ionic currents do not vary fully randomly in STG neurons (e.g. the $g_{K}$ and $g_{A}$ maximal conductances of potassium and A currents are correlated) [13,14]. Taking such correlations between maximal conductance values into consideration reduces the complexity of the search for appropriate parameters for the model of a given STG neuron. At the same time it should be noted that the experimentally determined ranges of conductance parameters of STG neurons are wide [15]. It has also been discovered that the correlations of maximal conductance values depend on the neuromodulatory context of the STG neurons. For example, following the cutting of the nerve connecting higher ganglia to the STG the $g_{K}$ and $g_{A}$ maximal conductances are no longer correlated [13].

\section{B. Modelling activity restoration in the pyloric network}

The pyloric network within the crustacean STG includes about 11 neurons ( 1 anterior burster - $\mathrm{AB}, 2$ pyloric dilator PD, 1 lateral pyloric - LP, 5 pyloric constrictor - PY, 1 ventricular dilator - VD and 1 inferior cardiac - IC neuron The number of PY neurons may vary with species) [1]. The combined activity of PD, LP and PY neurons is the typical pyloric rhythm (Fig. 1) that can be recorded from the lateral ventricular nerve (lvn) [1].

The pyloric network of the STG, in vitro, generates a spontaneous rhythm induced by the pacemaker core of the network formed by the $\mathrm{AB}$ and two PD neurons [1]. The spontaneous rhythm is active if the STG is connected through the stomatogastric nerve (stn) to three higher ganglia (the paired Comissural Ganglia - CoG, and the Oesophageal 


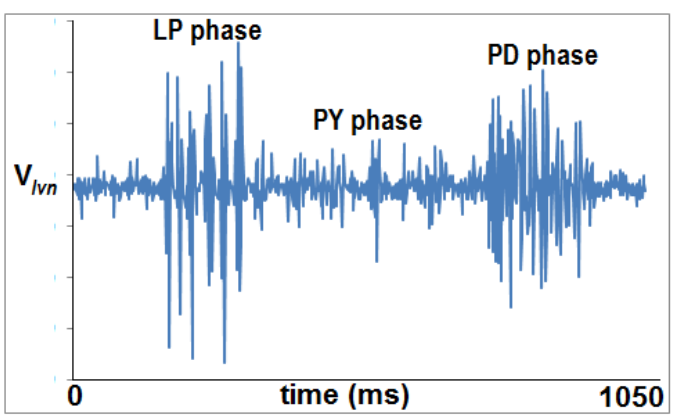

Fig. 1. Spontaneous pyloric rhythm recorded from the lvn of a crab STG. The LP, PY and PD phases of the rhythm are identified.

Ganglion - OG). The spontaneous rhythm stops if the stn is cut or blocked (e.g. by bathing a portion of the stn in sucrose solution) - this is called de-centralisation [1,6]. Following a silent period of $12-24$ hours the pyloric rhythm generated by the STG gets spontaneously reactivated. This restoration of neural activity in the pyloric neural network is due to changes in the participating neurons.

The main impact of de-centralisation of the STG is the stopping of the modulatory (e.g. proctolin, dopamine) input that originates from neurons with cell bodies located in the CoGs and OG [1,6]. A key short-term (sub-second) effect of neuromodulation is the increased release of $\mathrm{Ca}^{2+}$ ions from intracellular stores. Normally the cells contain $\mathrm{Ca}^{2+}$ ions at very low concentration in their cytoplasm. Thus the relatively large volume release of $\mathrm{Ca}^{2+}$ ions changes very much the calcium concentration inside of the cell, which in turn alters the equilibrium potential of $\mathrm{Ca}^{2+}$ ions in the cell (for other ions the equilibrium potential is stable due to the relatively large concentration of these ions both inside and outside of the cell). The shift in the equilibrium potential can alter significantly the dynamics of calcium ion currents and thus alter the overall dynamics of the membrane potential change of the neuron. There are also other ionic currents (e.g. potassium) which depend on the availability of calcium ions required for the activation of the respective ionic channel molecules. The lack of neuromodulation reduces very much the intracellular calcium concentration and consequently the impact of calcium and calcium-dependent ionic currents on the membrane potential dynamics of the neuron. In addition to this the ionic currents directly dependent on neuromodulators also stop. It is assumed that these are the effects that lead to ceasing of the activity of the pyloric rhythm of the STG $[1,6]$.

In the longer-term (hours) the impact of de-centralisation on STG neurons is the change in the regulation of patterns of gene transcription due to the lack of activation of neuromodulator-induced molecular signalling pathways that activate and/or inactivate specific transcription factors [13]. This change in the transcription regulation may lead to changed levels of transcription of mRNAs required for the synthesis of ion channel molecules and consequently to changes in the conductances of ionic currents in STG neurons.

Previous models of the restoration of the activity in the pyloric network assume that the internal calcium ion release mechanism of the neurons gets altered following de- centralisation [7-9]. These models capture the change in the calcium ion release mechanism by assuming an activity or neuromodulator sensor and a calcium pump. The dynamics of these leads to the change in the parameters of the dynamics of calcium release from intracellular stores. Another model assumes that the calcium and potassium conductances change in an activity-dependent manner [6]. The impact of neuromodulation is implemented in these models by considering a separate neuromodulation-dependent ionic current $\left(\mathrm{I}_{\mathrm{MI}}\right)$, which gets set to zero following the decentralisation of the STG [6-9]. Following the modelling the de-centralisation, when the changes to the calcium release mechanism become sufficient the restored levels of calcium ion currents and intracellular $\mathrm{Ca}^{2+}$ concentration trigger the restart of the activity of individual neurons and of the pyloric rhythm activity.

\section{Computational Model of the Pyloric Network}

Here we describe a model of the crustacean pyloric network following the approach of previous models based on $\mathrm{HH}$ model neurons $[6,10]$. The network includes models of AB, PD, LP and PY neurons. The key difference of our model from previous models is that we included into the model separate model neurons for each considered neuron of the pyloric circuit, i.e. we have 2 PD and 5 PY model neurons in our network model. We considered this important as there are differences between real neurons of the same type and consequently these neurons are not fully synchronised all time and such differences in the activity of neurons belonging to the same type potentially may be functionally significant for the behaviour of the network. Previous models typically assume identical PD neurons or PY neurons and simulate these in network models using a single corresponding model neuron $[6,10]$.

We set the models of the considered neurons and the parameters of these models using data reported in relevant papers in the literature, in particular our $\mathrm{AB}$ and $\mathrm{PD}$ neurons follow the modelling assumptions of Soto-Trevino et al [10], and our LP and PY neurons follow the modelling assumptions of Golowasch et al [6]. We also included slow and fast synaptic connection currents (slow: PD to LP, PD to PY; fast: LP to PD, AB to LP, PY to LP, AB to PY, LP to PY) and gap junction currents between appropriate neurons (between $P Y$ neurons, $\mathrm{PD}$ neurons and $\mathrm{PD}$ and $\mathrm{AB}$ neurons). Some of the parameter values were slightly changed compared to the values reported in the literature following the analysis of the behaviour of the modelled pyloric network. Each neuron was modelled using two compartments the axon and the soma/dendrite. Each axon compartment model included sodium $\left(g_{N a X}\right)$, potassium $\left(g_{K X}\right)$ and leak $\left(g_{L X}\right)$ currents (corresponding conductances in parentheses). The AB and PD model neurons soma included the following ionic currents: delayed rectifier potassium $\left(g_{K}\right)$, calcium-dependent potassium $\left(g_{K C a}\right)$, transient potassium $\left(g_{A}\right)$, persistent sodium $\left(g_{N a P}\right)$, transient calcium $\left(g_{\mathrm{CaT}}\right)$, persistent calcium $\left(g_{\mathrm{CaS}}\right)$, hyperpolarisation activated inward current $\left(g_{H}\right)$, leak $\left(g_{L}\right)$ and proctolin (neuromodulation) induced current $\left(g_{P}\right)$ only in the case of the AB. The LP and PY model neurons soma included the following currents: delayed rectifier potassium $\left(g_{K}\right)$, 
transient potassium $\left(g_{A}\right)$, calcium $\left(g_{C a}\right)$, hyper-polarisation activated inward current $\left(g_{H}\right)$, leak $\left(g_{L}\right)$ and proctolin (neuromodulation) induced current $\left(g_{P}\right)$ only in the case of the LP. Note that our proctolin induced current is the equivalent of the neuromodulation induced current $\left(\mathrm{I}_{\mathrm{MI}}\right)$ used in previous models [6-9].

When setting conductance parameters (maximal conductances) we took into consideration the experimentally determined correlations between conductance parameters of ionic channels ( $g_{K}$ is correlated with $g_{H}, g_{A}$, and $g_{N a P}$; and $g_{C a S}$ is correlated with $g_{C a T}$ ). The correlation values that we used were taken from Temporal et al [16] or calculated from the reported values in Soto-Trevino et al [10]. The two PD neurons have their parameters set slightly differently and the same applies to the five different PY neurons as well. The default parameters that we used for each model neuron are listed in Table I and Table II, the parameters include the default maximal conductance values, the values of equilibrium potentials and the values of the parameters of inf and $\tau$ functions for each channel openness $(m)$ and activation $(h)$ probability determining functions. We consider important reporting the parameter values in order to support the replication of our results.

In addition to the equations describing the change of membrane potential difference (see (1)) and the open and activation probabilities of the channels (see (2)), we also considered the equation below to capture the change in the intracellular concentration of calcium ions in the $\mathrm{AB}$ and $\mathrm{PD}$ neurons, following Soto-Trevino et al [10].

$\tau_{C a} \cdot d \operatorname{ConcC} a(t) / d t=-F \cdot I_{C a}-\operatorname{ConcCa}(t)+C_{0}$

where $I_{C a}$ is the total calcium current resulting from the sum of the transient and persistent calcium currents. The calcium equilibrium potential depends on the intracellular calcium concentration as follows [10]

$E_{C a}=(R \cdot T /(z \cdot F)) \cdot \ln (\mathrm{CaOut} / \mathrm{CaConc})$

where $\mathrm{R}=8312.47215 \mathrm{~mJ} /(\mathrm{K} \cdot \mathrm{Mol}), \mathrm{z}=2, \mathrm{~T}=284.069 \mathrm{~K}$, and $\mathrm{F}=96485.3399$ (Coulomb / Mol).

The equations describing the synaptic currents and the open probability of the corresponding conductance are as follows

$\left.\left.I_{s y n}=g_{s y n} \cdot m_{s y n} \cdot\left(V^{\text {target }}-E_{s y n}\right)\right)\right)$

for fast synapses $m_{s y n}$ follows the equation

$d m_{s y n}(t) / d t=k_{I} \cdot\left(1-m_{\text {syn }}(t)\right) /\left(1+\exp \left(s_{\text {syn }} \cdot\left(E_{\text {fast }}-V^{\text {target }}\right)\right)\right)$

for slow synapses $m_{s y n}$ follows the equation

$$
d m_{s y n}(t) / d t=k_{l} \cdot\left(1-m_{s y n}(t)\right) /\left(1+\exp \left(s_{s y n} \cdot\left(E_{\text {fast }}-V^{\text {target }}\right)\right)\right)
$$

$-k_{2} \cdot m_{s y n}(t)$

The current between the soma and axon is calculated as

$I_{\text {soma-axon }}=g_{\text {soma-axon }} \cdot\left(V^{\text {soma }}-V^{\text {axon }}\right)$

The differential equations describing the behaviour of the modelled neurons were solved using a $4^{\text {th }}$ order Runge-Kutta method with adaptive step size. The whole model was implemented in Delphi in order to increase the execution speed of the simulations (the code is available on request from the authors).

TABLE I. CONDUCTANCE AND RELATED PARAMETERS OF THE MODELLED PYLORIC NEURONS

\begin{tabular}{|c|c|c|c|}
\hline Param & Value & Param & Value \\
\hline $\begin{array}{l}C^{\mathrm{LP}, \mathrm{PY}} \\
\mathrm{C}^{\mathrm{AB}} \\
\mathrm{C}^{\mathrm{PD}} \\
\end{array}$ & $\begin{array}{c}0.2 \times 10^{-3} \mu \mathrm{F} \\
9 \times 10^{-3} \mu \mathrm{F} \\
12 \times 10^{-3} \mu \mathrm{F}\end{array}$ & $\begin{array}{l}\mathrm{F}^{\mathrm{AB}} \\
\mathrm{F}^{\mathrm{PD}}\end{array}$ & $\begin{array}{l}0.418 \mu \mathrm{M} / \mathrm{nA} \\
0.515 \mu \mathrm{M} / \mathrm{nA}\end{array}$ \\
\hline $\begin{array}{l}E_{L}^{L P, P Y} \\
E_{L}^{A B} \\
E_{L}{ }^{P D}\end{array}$ & $\begin{array}{l}-68 \mathrm{mV} \\
-50 \mathrm{mV} \\
-55 \mathrm{mV}\end{array}$ & $\mathrm{E}_{\mathrm{K}}$ & $-80 \mathrm{mV}$ \\
\hline $\mathrm{E}_{\mathrm{Ca}}$ & $\begin{array}{c}120 \mathrm{mV} \text { or variable - } \\
\text { see equation }(5)\end{array}$ & 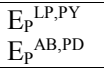 & $\begin{array}{c}-10 \mathrm{mV} \\
0 \mathrm{mV}\end{array}$ \\
\hline $\mathrm{E}_{\mathrm{H}}$ & $-20 \mathrm{mV}$ & $\mathrm{E}_{\mathrm{KCa}}$ & $-80 \mathrm{mV}$ \\
\hline $\mathrm{E}_{\mathrm{NaP}}$ & $50 \mathrm{mV}$ & $\mathrm{E}_{\mathrm{A}}$ & $-80 \mathrm{mV}$ \\
\hline $\mathrm{C}_{0}^{\mathrm{AB}, \mathrm{PD}}$ & $0.5 \mu \mathrm{M}$ & $\begin{array}{l}\tau_{\mathrm{Ca}}{ }^{\mathrm{AB}} \\
\tau_{\mathrm{Ca}}{ }^{\mathrm{PD}}\end{array}$ & $\begin{array}{l}303 \mathrm{~ms} \\
300 \mathrm{~ms}\end{array}$ \\
\hline $\mathrm{g}_{\mathrm{L}}^{\mathrm{LP}}$ & $0.025 \times 10^{-3} \mathrm{mS}$ & $\mathrm{g}_{\mathrm{K}}^{\mathrm{LP}}$ & $0.1 \times 10^{-3}$ \\
\hline $\mathrm{g}_{\mathrm{A}}^{\mathrm{LP}}$ & $0.01 \times 10^{-3} \mathrm{mS}$ & $\mathrm{g}_{\mathrm{H}}^{\mathrm{LP}}$ & $0.005 \times 10^{-3}$ \\
\hline $\mathrm{g}_{\mathrm{P}}^{\mathrm{LP}}$ & $0.004 \times 10^{-3} \mathrm{mS}$ & $\mathrm{g}_{\mathrm{Ca}}^{\mathrm{LP}}$ & $0.107 \times 10^{-3} \mathrm{mS}$ \\
\hline $\mathrm{g}_{\mathrm{K}}{ }^{\mathrm{PY}}$ & $\begin{array}{c}0.081 \times 10^{-3}, \mathrm{mS} \\
0.101 \times 10^{-3} \mathrm{mS} \\
0.121 \times 10^{-3} \mathrm{mS} \\
0.141 \times 10^{-3} \mathrm{mS} \\
0.161 \times 10^{-3} \mathrm{mS}\end{array}$ & $\mathrm{g}_{\mathrm{H}}^{\mathrm{PY}}$ & $0.087 \times \mathrm{g}_{\mathrm{K}}{ }^{\mathrm{PY}}$ \\
\hline $\mathrm{g}_{\mathrm{A}}^{\mathrm{PY}}$ & $0.8875 \times \mathrm{g}_{\mathrm{K}}{ }^{\mathrm{PY}}$ & $\mathrm{g}_{\mathrm{L}}{ }^{\mathrm{PY}}$ & $0.015 \times 10^{-3} \mathrm{mS}$ \\
\hline $\mathrm{g}_{\mathrm{Ca}}^{\mathrm{PY}}$ & $0.2 \times 10^{-3} \mathrm{mS}$ & $\mathrm{g}_{\text {gap }}{ }^{\mathrm{PY}}$ & $0.01 \times 10^{-3} \mathrm{mS}$ \\
\hline $\mathrm{g}_{\mathrm{CaT}}{ }^{\mathrm{AB}}$ & $59.064 \times 10^{-3} \mathrm{mS}$ & $\mathrm{g}_{\mathrm{H}}^{\mathrm{AB}}$ & $0.054 \times 10^{-3} \mathrm{mS}$ \\
\hline $\mathrm{g}_{\mathrm{CaS}}{ }^{\mathrm{AB}}$ & $9.63 \times 10^{-3} \mathrm{mS}$ & $\mathrm{g}_{\mathrm{K}}^{\mathrm{AB}}$ & $1890 \times 10^{-3} \mathrm{mS}$ \\
\hline $\mathrm{g}_{\mathrm{NaP}}{ }^{\mathrm{AB}}$ & $2.7 \times 10^{-3} \mathrm{mS}$ & $\mathrm{g}_{\mathrm{KCa}}{ }^{\mathrm{AB}}$ & $6000 \times 10^{-3} \mathrm{mS}$ \\
\hline $\mathrm{g}_{\mathrm{A}}^{\mathrm{AB}}$ & $21.6 \times 10^{-3} \mathrm{mS}$ & $\mathrm{g}_{\mathrm{L}}{ }^{\mathrm{AB}}$ & $0.045 \times 10^{-3} \mathrm{mS}$ \\
\hline $\mathrm{g}_{\mathrm{P}}{ }^{\mathrm{AB}}$ & $570 \times 10^{-3} \mathrm{mS}$ & $\mathrm{g}_{\text {gap }} \mathrm{AB}$ & $0.75 \times 10^{-3} \mathrm{mS}$ \\
\hline $\mathrm{g}_{\text {soma-axon }} \mathrm{AB}$ & $0.3 \times 10^{-3} \mathrm{mS}$ & $\mathrm{g}_{\mathrm{CaT}}{ }^{\mathrm{PD}}$ & $\begin{array}{l}24.075 \times 10^{-3} \mathrm{mS} \\
16.585 \times 10^{-3} \mathrm{mS}\end{array}$ \\
\hline $\mathrm{g}_{\mathrm{CaS}}{ }^{\mathrm{PD}}$ & $(8 / 3) \times \mathrm{g}_{\mathrm{CaT}}{ }^{\mathrm{PD}}$ & $\mathrm{g}_{\mathrm{K}}^{\mathrm{PD}}$ & $\begin{array}{l}1576.8 \times 10^{-3} \mathrm{mS} \\
1000.8 \times 10^{-3} \mathrm{mS}\end{array}$ \\
\hline $\mathrm{g}_{\mathrm{NaP}}{ }^{\mathrm{PD}}$ & $(25 / 9) \times \mathrm{g}_{\mathrm{K}}{ }^{\mathrm{PD}} \times 10^{-3}$ & $\mathrm{~g}_{\mathrm{A}}{ }^{\mathrm{PD}}$ & $0.025 \times \mathrm{g}_{\mathrm{K}}{ }^{\mathrm{PD}}$ \\
\hline $\mathrm{g}_{\mathrm{KCa}}{ }^{\mathrm{PD}}$ & $251.85 \times 10^{-3} \mathrm{mS}$ & $\mathrm{g}_{\mathrm{H}}{ }^{\mathrm{PD}}$ & $(50 / 9) \times \mathrm{g}_{\mathrm{A}}{ }^{\mathrm{PD}} \times 10^{-3}$ \\
\hline $\mathrm{g}_{\mathrm{L}}{ }^{\mathrm{PD}}$ & $0.105 \times 10^{-3} \mathrm{mS}$ & $g_{\text {gap- } A B} P D$ & $0.75 \times 10^{-3} \mathrm{mS}$ \\
\hline $\mathrm{g}_{\text {soma-axon }}{ }^{\mathrm{PD}}$ & $1.05 \times 10^{-3} \mathrm{mS}$ & $\mathrm{g}_{\text {gap-PD }}{ }^{\mathrm{PD}}$ & $0.001 \times 10^{-3} \mathrm{mS}$ \\
\hline $\begin{array}{l}\mathrm{C}^{\mathrm{LP}, \mathrm{PY}} \\
\mathrm{C}^{\mathrm{AB}}\end{array}$ & $\begin{array}{c}0.02 \mu \mathrm{F} \\
1.5 \times 10^{-3} \mu \mathrm{F}\end{array}$ & $\mathrm{E}_{\mathrm{K}}$ & $-80 \mathrm{mV}$ \\
\hline
\end{tabular}




\begin{tabular}{|c|c|c|c|}
\hline Param & Value & Param & Value \\
\hline $\mathrm{C}^{\mathrm{PD}}$ & $6 \times 10^{-3} \mu \mathrm{F}$ & & \\
\hline $\begin{array}{l}\mathrm{E}_{\mathrm{Na}}^{\mathrm{LP}, \mathrm{PY}} \\
\mathrm{E}_{\mathrm{Na}}{ }^{\mathrm{AB}}\end{array}$ & $\begin{array}{l}20 \mathrm{mV} \\
50 \mathrm{mV}\end{array}$ & $\begin{array}{l}\mathrm{E}_{\mathrm{L}}^{\mathrm{LP}, \mathrm{PY}} \\
\mathrm{E}_{\mathrm{L}}^{\mathrm{AB}}\end{array}$ & $\begin{array}{l}-68 \mathrm{mV} \\
-60 \mathrm{mV}\end{array}$ \\
\hline $\begin{array}{l}\mathrm{g}_{\mathrm{LX}}{ }^{\mathrm{LP}, \mathrm{PY}} \\
\mathrm{g}_{\mathrm{LX}}^{\mathrm{AB}} \\
\mathrm{g}_{\mathrm{LX}}{ }^{\mathrm{PD}}\end{array}$ & $\begin{array}{c}0.0075 \times 10^{-3} \mathrm{mS} \\
0.0018 \times 10^{-3} \mathrm{mS} \\
0.00081 \times 10^{-3} \mathrm{mS}\end{array}$ & $\begin{array}{l}\mathrm{g}_{\mathrm{NaX}} \mathrm{LP}^{\mathrm{LPY}} \\
\mathrm{g}_{\mathrm{NaX}} \mathrm{AB}^{\mathrm{AB}} \\
\mathrm{g}_{\mathrm{NaX}}{ }^{\mathrm{PD}}\end{array}$ & $\begin{array}{c}0.3 \times 10^{-3} \mathrm{mS} \\
300 \times 10^{-3} \mathrm{mS} \\
1110 \times 10^{-3} \mathrm{mS}\end{array}$ \\
\hline $\begin{array}{l}\mathrm{g}_{\mathrm{KX}}{ }^{\mathrm{LP}, \mathrm{PY}} \\
\mathrm{g}_{\mathrm{KX}}{ }^{\mathrm{AB}} \\
\mathrm{g}_{\mathrm{KX}}{ }^{\mathrm{PD}} \\
\end{array}$ & $\begin{array}{c}4 \times 10^{-3} \mathrm{mS} \\
52.5 \times 10^{-3} \mathrm{mS} \\
150 \times 10^{-3} \mathrm{mS} \\
\end{array}$ & $\mathrm{g}_{\text {soma-axon }}$ & $0.01 \times 10^{-3} \mathrm{mS}$ \\
\hline $\mathrm{g}_{\mathrm{LP}-\mathrm{PD}}{ }^{\mathrm{syn}}$ & $0.004 \times 10^{-3} \mathrm{mS}$ & $\mathrm{g}_{\mathrm{PY}-\mathrm{LP}} \mathrm{syn}^{\mathrm{syn}}$ & $(0.015 / 9.5) \times 10^{-3} \mathrm{mS}$ \\
\hline $\mathrm{g}_{\mathrm{AB}-\mathrm{LP}} \mathrm{syn}^{\mathrm{syn}}$ & $(0.015 / 1.9) \times 10^{-3} \mathrm{mS}$ & $\mathrm{g}_{\mathrm{AB}-\mathrm{PY}} \mathrm{syn}^{\mathrm{syn}}$ & $(0.027 / 1.6) \times 10^{-3} \mathrm{mS}$ \\
\hline $\mathrm{g}_{\mathrm{LP}-\mathrm{PY}}{ }^{\mathrm{syn}}$ & $0.015 \times 10^{-3} \mathrm{mS}$ & $\mathrm{g}_{\mathrm{PD}-\mathrm{PY}}^{\mathrm{syn}}$ & $(0.015 / 1.6) \times 10^{-3} \mathrm{mS}$ \\
\hline $\mathrm{g}_{\mathrm{PD}-\mathrm{LP}} \mathrm{syn}^{\mathrm{syn}}$ & $(0.015 / 3.8) \times 10^{-3} \mathrm{mS}$ & $\mathrm{E}_{\mathrm{syn}}$ & $-75 \mathrm{mV}$ \\
\hline $\mathrm{s}_{\text {fast }}^{\text {syn }}$ & $0.2 \mathrm{mV}^{-1}$ & $\mathrm{~S}_{\text {slow }}{ }^{\text {syn }}$ & $1 \mathrm{mV}^{-1}$ \\
\hline $\mathrm{E}_{\text {fast }}^{\text {syn }}$ & $-50 \mathrm{mV}$ & $\mathrm{E}_{\text {slow }}{ }^{\text {syn }}$ & $-55 \mathrm{mV}$ \\
\hline $\mathrm{k}_{1}^{\text {syn }}$ & $1 \mathrm{~ms}^{-1}$ & $\begin{array}{l}\mathrm{k}_{2, \mathrm{PD}-\mathrm{LP}}^{\mathrm{syn}} \\
\mathrm{k}_{2, \mathrm{PD}-} \\
\mathrm{PY}^{\text {syn }}\end{array}$ & $\begin{array}{c}0.03 \mathrm{~ms}^{-1} \\
0.008 \mathrm{~ms}^{-1}\end{array}$ \\
\hline
\end{tabular}

All equations of inf and $\tau$ functions follow the form of (3), with the exception of the $\tau$ function for $h_{N a}$ in the model axon for $\mathrm{AB}$ and $\mathrm{PD}$ neurons, in which case the equation is [10]

$h_{N a X, \tau}(V)=\left(h_{N a X, \tau, \min }+\left(h_{N a X, \tau, \max }-h_{N a X, \tau, \min }\right)\right.$.

$\left(1 /\left(1+\exp \left(h_{\mathrm{NaX}, \tau, \alpha} \cdot\left(V_{h, \mathrm{NaX}, \tau, \mathrm{mid}}-V\right)\right)\right)\right) \cdot\left(h_{\mathrm{NaX}, \tau, \min }+\right.$

$\left(h_{N a X 2, \tau, \max }-h_{N a X 2, \tau, \min }\right) \cdot\left(1 /\left(1+\exp \left(h_{N a X 2, \tau, \alpha} \cdot\left(V_{h, N a X 2, \tau, \text { mid }}-V\right)\right)\right)\right)$

TABLE II. PARAMETER VALUES OF THE INF AND $\tau$ FUNCTIONS

\begin{tabular}{|c|c|c|c|}
\hline Param & Value & Param & Value \\
\hline $\mathrm{m}_{\mathrm{Ca}, \mathrm{inf}, \alpha}$ & 0.205 & $\mathrm{~m}_{\mathrm{Ca}, \text { inf,max }}$ & 1 \\
\hline $\mathrm{V}_{\mathrm{m}, \mathrm{Ca}, \text { inf,mid }}$ & -61.2 & $\mathrm{~m}_{\mathrm{Ca}, \text { inf,min }}$ & 0 \\
\hline $\mathrm{m}_{\mathrm{Ca}, \tau, \alpha}$ & -0.2 & $\mathrm{~m}_{\mathrm{Ca}, \tau, \text { max }}$ & 30 \\
\hline $\mathrm{V}_{\mathrm{m}, \mathrm{Ca}, \tau, \mathrm{\tau} \text { mid }}$ & -65 & $\mathrm{~m}_{\mathrm{Ca}, \tau, \text { min }}$ & 25 \\
\hline $\mathrm{h}_{\mathrm{Ca}, \mathrm{inf}, \alpha}$ & 0.15 & $\mathrm{~h}_{\mathrm{Ca}, \text { inf, } \max }$ & 1 \\
\hline $\mathrm{V}_{\mathrm{h}, \mathrm{Ca} \text {,inf,mid }}$ & -75 & $\mathrm{~h}_{\mathrm{Ca}, \text {,inf,min }}$ & 0 \\
\hline $\mathrm{h}_{\mathrm{Ca}, \tau, \alpha}$ & 0 & $\mathrm{~h}_{\mathrm{Ca}, \tau, \text { max }}$ & 150 \\
\hline $\mathrm{V}_{\mathrm{h}, \mathrm{Ca}, \tau, \text { mid }}$ & 0 & $\mathrm{~h}_{\mathrm{Ca}, \tau_{\text {, min }}}$ & 150 \\
\hline $\mathrm{m}_{\mathrm{K}-\mathrm{LPPY}, \text { inf }, \alpha}$ & 0.1 & $\mathrm{~m}_{K-L P P Y, \text { inf,max }}$ & 1 \\
\hline $\mathrm{V}_{\mathrm{m}, \mathrm{K}-\mathrm{LPPY}, \text { inf,mid }}$ & -35 & $\mathrm{~m}_{\mathrm{K}-\mathrm{LPPY}, \mathrm{inf}, \min }$ & 0 \\
\hline $\mathrm{m}_{\mathrm{K}-\mathrm{LPPY}, \tau, \alpha}$ & -0.125 & $\mathrm{~m}_{\mathrm{K}-\mathrm{LPPY}, \tau, \max }$ & 57 \\
\hline $\mathrm{V}_{\mathrm{m}, \mathrm{K}-\mathrm{LPPY}, \tau, \mathrm{\tau}, \mathrm{mid}}$ & -54 & $\mathrm{~m}_{\mathrm{K}-\mathrm{LPPY}, \tau, \text { min }}$ & 2 \\
\hline $\mathrm{m}_{\mathrm{A}-\mathrm{PY}, \mathrm{inf}, \alpha}$ & 0.2 & $\mathrm{~m}_{\mathrm{A}-\mathrm{PY}, \text { inf, } \text { max }}$ & 1 \\
\hline $\mathrm{V}_{\mathrm{m}, \mathrm{A}-\mathrm{PY}, \text { inf,mid }}$ & -51 & $\mathrm{~m}_{\mathrm{A}-\mathrm{PY}, \text { inf,min }}$ & 0 \\
\hline $\mathrm{m}_{\mathrm{A}-\mathrm{LP}, \mathrm{inf}, \alpha}$ & 0.2 & $\mathrm{~m}_{\mathrm{A}-\mathrm{LP}, \text { inf, } \text {, }}$ & 1 \\
\hline
\end{tabular}

\begin{tabular}{|c|c|c|c|}
\hline Param & Value & Param & Value \\
\hline $\mathrm{V}_{\mathrm{m}, \mathrm{A}-\mathrm{LP}, \mathrm{inf}, \mathrm{mid}}$ & -60 & $\mathrm{~m}_{\mathrm{A}-\mathrm{LP}, \text {,inf,min }}$ & 0 \\
\hline $\mathrm{m}_{\mathrm{A}-\mathrm{LPPY}, \tau, \alpha}$ & 0 & $\mathrm{~m}_{\mathrm{A}-\mathrm{LPPY}, \tau, \max }$ & 0.1 \\
\hline $\mathrm{V}_{\mathrm{m}, \mathrm{A}-\mathrm{LPPY}, \tau, \mathrm{t} \text { mid }}$ & 0 & $\mathrm{~m}_{\mathrm{A}-\mathrm{LPPY}, \tau, \min }$ & 0.1 \\
\hline $\mathrm{h}_{\mathrm{A}-\mathrm{LPPY}, \mathrm{inf}, \alpha}$ & -0.18 & $\mathrm{~h}_{\mathrm{A}-\mathrm{LPPY}, \mathrm{inf}, \max }$ & 1 \\
\hline $\mathrm{V}_{\mathrm{h}, \mathrm{A}-\mathrm{LPPY}, \text { inf,mid }}$ & -68 & $\mathrm{~h}_{\mathrm{A}-\mathrm{LPPY}, \text { inf,min }}$ & 0 \\
\hline $\mathrm{h}_{\mathrm{A}-\mathrm{LPPY}, \tau, \alpha}$ & 0 & $\mathrm{~h}_{\mathrm{A}-\mathrm{LPPY}, \tau, \text { max }}$ & 50 \\
\hline $\mathrm{V}_{\mathrm{h}, \mathrm{A}-\mathrm{LPPY}, \tau, \text { mid }}$ & 0 & $\mathrm{~h}_{\mathrm{A}-\mathrm{LPPY}, \tau, \text { min }}$ & 50 \\
\hline $\mathrm{m}_{P-\mathrm{LP}, \mathrm{inf}, \alpha}$ & 0.2 & $\mathrm{~m}_{\text {P-LP,inf, max }}$ & 1 \\
\hline $\mathrm{V}_{\mathrm{m}, \mathrm{P}-\mathrm{LP}, \text { inf,mid }}$ & -55 & $\mathrm{~m}_{\mathrm{P}-\mathrm{LP} \text {,inf,min }}$ & 0 \\
\hline $\mathrm{m}_{\mathrm{P}-\mathrm{LP}, \tau, \alpha}$ & 0 & $\mathrm{~m}_{\mathrm{P}-\mathrm{LP}, \tau, \mathrm{max}}$ & 6 \\
\hline $\mathrm{V}_{\mathrm{m}, \mathrm{P}-\mathrm{LP}, \tau, \mathrm{\tau} \text { mid }}$ & 0 & $\mathrm{~m}_{\mathrm{P}-\mathrm{LP}, \tau, \mathrm{\tau} \text {, in }}$ & 6 \\
\hline $\mathrm{m}_{\mathrm{NaX}-\mathrm{LPPY}, \mathrm{inf}, \alpha}$ & 0.1 & $\mathrm{~m}_{\mathrm{NaX}-\mathrm{LPPY}, \text { inf,max }}$ & 1 \\
\hline $\mathrm{V}_{\mathrm{m}, \mathrm{NaX}-\mathrm{LPPY}, \text { inf,mid }}$ & -42 & $\mathrm{~m}_{\mathrm{NaX}-\mathrm{LPPY}, \text { inf,min }}$ & 0 \\
\hline $\mathrm{m}_{\mathrm{NaX}-\mathrm{LPPY}, \tau, \alpha}$ & 0 & $\mathrm{~m}_{\mathrm{NaX}-\mathrm{LPPY}, \tau, \max }$ & 0.25 \\
\hline $\mathrm{V}_{\mathrm{m}, \mathrm{NaX}-\mathrm{LPPY}, \tau, \mathrm{mid}}$ & 0 & $\mathrm{~m}_{\mathrm{NaX}-\mathrm{LPPY}, \tau, \min }$ & 0.25 \\
\hline $\mathrm{h}_{\mathrm{NaX}-\mathrm{LPPY}, \mathrm{inf}, \alpha}$ & -0.13 & $\mathrm{~h}_{\mathrm{NaX}-\mathrm{LPPY}, \text { inf, max }}$ & 1 \\
\hline $\mathrm{V}_{\mathrm{h}, \mathrm{NaX}-\mathrm{LPPY}, \text { inf,mid }}$ & -50 & $\mathrm{~h}_{\mathrm{NaX}-\mathrm{LPPY}, \text { inf,min }}$ & 0 \\
\hline $\mathrm{h}_{\mathrm{NaX}-\mathrm{LPPY}, \tau, \alpha}$ & 0.12 & $\mathrm{~h}_{\mathrm{NaX}-\mathrm{LPPY}, \tau, \max }$ & 10 \\
\hline $\mathrm{V}_{\mathrm{h}, \mathrm{NaX} \text {-LPPY, }, \text {,mid }}$ & -77 & $\mathrm{~h}_{\mathrm{NaX}-\mathrm{LPPY}, \tau, \text { min }}$ & 0 \\
\hline $\mathrm{m}_{\mathrm{KX}-\mathrm{LPPY}, \mathrm{inf}, \alpha}$ & 0.2 & $\mathrm{~m}_{\mathrm{KX} \text {-LPPY,inf,max }}$ & 1 \\
\hline $\mathrm{V}_{\mathrm{m}, \mathrm{KX}-\mathrm{LPPY}, \mathrm{inf}, \text { mid }}$ & -41 & $\mathrm{~m}_{\mathrm{KX} \text {-LPPY,inf,min }}$ & 0 \\
\hline $\mathrm{m}_{\mathrm{KX} \text {-LPPY }, \tau, \alpha}$ & -0.05 & $\mathrm{~m}_{\mathrm{KX}-\mathrm{LPPY}, \tau, \text { max }}$ & 22.7 \\
\hline $\mathrm{V}_{\mathrm{m}, \mathrm{KX}-\mathrm{LPPY}, \tau, \mathrm{t} \text { mid }}$ & 58 & $\mathrm{~m}_{\mathrm{KX}-\mathrm{LPPY}, \tau, \mathrm{min}}$ & 12.2 \\
\hline $\mathrm{m}_{\mathrm{NaX}-\mathrm{ABPD}, \mathrm{inf}, \alpha}$ & $1 / 5.29$ & $\mathrm{~m}_{\mathrm{NaX}-\mathrm{ABPD}, \text { inf,max }}$ & 1 \\
\hline $\mathrm{V}_{\mathrm{m}, \mathrm{NaX}-\mathrm{ABPD}, \text { inf,mid }}$ & -24.7 & $\mathrm{~m}_{\mathrm{NaX}-\mathrm{ABPD}, \mathrm{inf}, \min }$ & 0 \\
\hline $\mathrm{m}_{\mathrm{NaX}-\mathrm{ABPD}, \tau, \alpha}$ & $-1 / 25$ & $\mathrm{~m}_{\mathrm{NaX}-\mathrm{ABPD}, \tau, \max }$ & 1.32 \\
\hline $\mathrm{V}_{\mathrm{m}, \mathrm{NaX}-\mathrm{ABPD}, \tau, \mathrm{mid}}$ & -120 & $\mathrm{~m}_{\mathrm{NaX}-\mathrm{ABPD}, \tau, \text { min }}$ & 0.06 \\
\hline $\mathrm{h}_{\mathrm{NaX}-\mathrm{ABPD}, \text { inf }, \alpha}$ & $-1 / 5.18$ & $\mathrm{~h}_{\mathrm{NaX}-\mathrm{ABPD}, \text { inf,max }}$ & 1 \\
\hline $\mathrm{V}_{\mathrm{h}, \mathrm{NaX}-\mathrm{ABPD} \text {,inf,mid }}$ & -48.9 & $\mathrm{~h}_{\mathrm{NaX}-\mathrm{ABPD} \text {,inf,min }}$ & 0 \\
\hline $\mathrm{h}_{\mathrm{NaX}-\mathrm{ABPD}, \tau, \alpha}$ & $1 / 10$ & $\mathrm{~h}_{\mathrm{NaX}-\mathrm{ABPD}, \tau, \text { max }}$ & 0.67 \\
\hline $\mathrm{V}_{\mathrm{h}, \mathrm{NaX}-\mathrm{ABPD}, \tau, \text { mid }}$ & -62.9 & $\mathrm{~h}_{\mathrm{NaX}-\mathrm{ABPD}, \tau, \mathrm{t} \text { min }}$ & 0 \\
\hline $\mathrm{h}_{\mathrm{NaX2}-\mathrm{ABPD}, \tau, \alpha}$ & $-1 / 3.6$ & $\mathrm{~h}_{\mathrm{NaX2}-\mathrm{ABPD}, \tau, \max }$ & 2.5 \\
\hline $\mathrm{V}_{\mathrm{h}, \mathrm{NaX} 2 \mathrm{ABPD}, \tau, \text { mid }}$ & -34.9 & $\mathrm{~h}_{\mathrm{NaX2}-\mathrm{ABPD}, \tau, \min }$ & 1.5 \\
\hline$m_{K X-A B P D, \text { inf }, \alpha}$ & $1 / 11.8$ & $\mathrm{~m}_{\mathrm{KX}-\mathrm{ABPD} \text {,inf,max }}$ & 1 \\
\hline $\mathrm{V}_{\mathrm{m}, \mathrm{KX}-\mathrm{ABPD} \text {,inf,mid }}$ & -14.2 & $\mathrm{~m}_{\mathrm{KX}-\mathrm{ABPD} \text {,inf,min }}$ & 0 \\
\hline $\mathrm{m}_{\mathrm{KX}-\mathrm{ABPD}, \tau, \alpha}$ & $-1 / 19.2$ & $\mathrm{~m}_{\mathrm{KX}-\mathrm{ABPD}, \tau, \max }$ & 7.2 \\
\hline $\mathrm{V}_{\mathrm{m}, \mathrm{KX}-\mathrm{ABPD}, \tau, \text { mid }}$ & -28.3 & $\mathrm{~m}_{\mathrm{KX}-\mathrm{ABPD}, \tau, \text { min }}$ & 0.8 \\
\hline $\mathrm{m}_{\mathrm{CaT}, \mathrm{inf}, \alpha}$ & $1 / 7.2$ & $\mathrm{~m}_{\mathrm{CaT}, \mathrm{inf}, \max }$ & 1 \\
\hline $\mathrm{V}_{\mathrm{m}, \mathrm{CaT}, \text { inf,mid }}$ & -25 & $\mathrm{~m}_{\mathrm{CaT}, \mathrm{inf}, \min }$ & 0 \\
\hline $\mathrm{m}_{\mathrm{CaT}, \tau, \alpha}$ & $-1 / 17$ & $\mathrm{~m}_{\mathrm{CaT}, \tau, \max }$ & 55 \\
\hline
\end{tabular}




\begin{tabular}{|c|c|c|c|}
\hline Param & Value & Param & Value \\
\hline $\mathrm{V}_{\mathrm{m}, \mathrm{CaT}, \tau, \mathrm{mid}}$ & -58 & $\mathrm{~m}_{\mathrm{CaT}, \tau, \min }$ & 5.5 \\
\hline $\mathrm{h}_{\mathrm{CaT}, \text { inf, } \alpha}$ & $-1 / 7$ & $\mathrm{~h}_{\mathrm{CaT}, \text { inf,max }}$ & 1 \\
\hline $\mathrm{V}_{\mathrm{h}, \mathrm{CaT}, \text { inf,mid }}$ & -36 & $\mathrm{~h}_{\mathrm{CaT}, \text { inf,min }}$ & 0 \\
\hline $\mathrm{h}_{\mathrm{CaT}-\mathrm{AB}, \tau, \alpha}$ & $-1 / 16.9$ & $\mathrm{~h}_{\mathrm{CaT}-\mathrm{AB}, \tau, \max }$ & 87.5 \\
\hline $\mathrm{V}_{\mathrm{h}, \mathrm{CaT}-\mathrm{AB}, \tau, \mathrm{mid}}$ & -50 & $\mathrm{~h}_{\mathrm{CaT}-\mathrm{AB}, \tau, \min }$ & 12.5 \\
\hline $\mathrm{h}_{\mathrm{CaT}-\mathrm{PD}, \tau, \alpha}$ & $-1 / 16.9$ & $\mathrm{~h}_{\text {CaT-PD }, \tau, \max }$ & 350 \\
\hline $\mathrm{V}_{\mathrm{h}, \mathrm{CaT}-\mathrm{PD}, \tau \text {,mid }}$ & -50 & $\mathrm{~h}_{\mathrm{CaT}-\mathrm{PD}, \tau, \text { min }}$ & 275 \\
\hline $\mathrm{m}_{\mathrm{CaS}, \text { inf }, \alpha}$ & $1 / 8.5$ & $\mathrm{~m}_{\mathrm{CaS}, \text { inf,max }}$ & 1 \\
\hline $\mathrm{V}_{\mathrm{m}, \mathrm{CaS}, \text { inf,mid }}$ & -22 & $\mathrm{~m}_{\mathrm{CaS}, \text { inf,min }}$ & 0 \\
\hline $\mathrm{m}_{\mathrm{CaS}, \tau, \alpha}$ & $-1 / 26.4$ & $\mathrm{~m}_{\mathrm{CaS}, \tau, \max }$ & 16 \\
\hline $\mathrm{V}_{\mathrm{m}, \mathrm{CaS}, \tau, \mathrm{mid}}$ & -25.1 & $\mathrm{~m}_{\mathrm{CaS}, \tau, \min }$ & 2.9 \\
\hline $\mathrm{m}_{\mathrm{NaP}, \text { inf }, \alpha}$ & $1 / 8.2$ & $\mathrm{~m}_{\mathrm{NaP}, \text { inf, } \max }$ & 1 \\
\hline $\mathrm{V}_{\mathrm{m}, \mathrm{NaP}, \text { inf,mid }}$ & -26.8 & $\mathrm{~m}_{\mathrm{NaP}, \text { inf,min }}$ & 0 \\
\hline $\mathrm{m}_{\mathrm{NaP}, \tau, \alpha}$ & $-1 / 8.6$ & $\mathrm{~m}_{\mathrm{NaP}, \tau, \max }$ & 19.8 \\
\hline $\mathrm{V}_{\mathrm{m}, \mathrm{NaP}, \tau, \mathrm{mid}}$ & -26.5 & $\mathrm{~m}_{\mathrm{NaP}, \tau, \min }$ & 9.1 \\
\hline $\mathrm{h}_{\mathrm{NaP}, \text { inf, } \alpha}$ & $1 / 4.8$ & $\mathrm{~h}_{\mathrm{NaP}, \text { inf,max }}$ & 1 \\
\hline $\mathrm{V}_{\mathrm{h}, \mathrm{NaP}, \text { inf,mid }}$ & -48.5 & $\mathrm{~h}_{\mathrm{NaP}, \text { inf,min }}$ & 0 \\
\hline $\mathrm{h}_{\mathrm{NaP}, \tau, \alpha}$ & $1 / 11.7$ & $\mathrm{~h}_{\mathrm{NaP}, \tau, \max }$ & 666 \\
\hline $\mathrm{V}_{\mathrm{h}, \mathrm{NaP}, \tau, \text { mid }}$ & -33.6 & $\mathrm{~h}_{\mathrm{NaP}, \tau, \min }$ & 287 \\
\hline $\mathrm{m}_{\mathrm{H}, \mathrm{inf}, \alpha}$ & $-1 / 6$ & $\mathrm{~m}_{\mathrm{H}, \text { inf,max }}$ & 1 \\
\hline $\mathrm{V}_{\mathrm{m}, \mathrm{H} \text {,inf,mid }}$ & -70 & $\mathrm{~m}_{\mathrm{H}, \mathrm{inf}, \min }$ & 0 \\
\hline $\mathrm{m}_{\mathrm{H}, \tau, \alpha}$ & $1 / 8.73$ & $\mathrm{~m}_{\mathrm{H}, \tau, \max }$ & 1771 \\
\hline $\mathrm{V}_{\mathrm{m}, \mathrm{H}, \tau, \mathrm{mid}}$ & -42.2 & $\mathrm{~m}_{\mathrm{H}, \tau, \mathrm{min}}$ & 272 \\
\hline $\mathrm{m}_{\mathrm{K}-\mathrm{ABPD}, \mathrm{inf}, \alpha}$ & $1 / 11.8$ & $\mathrm{~m}_{\mathrm{K}-\mathrm{ABPD}, \text { inf,max }}$ & 1 \\
\hline $\mathrm{V}_{\mathrm{m}, \mathrm{K}-\mathrm{ABPD} \text {,inf,mid }}$ & -14.2 & $\mathrm{~m}_{\mathrm{K}-\mathrm{ABPD} \text {,inf,min }}$ & 0 \\
\hline $\mathrm{m}_{\mathrm{K}-\mathrm{ABPD}, \tau, \alpha}$ & $-1 / 19.2$ & $\mathrm{~m}_{\mathrm{K}-\mathrm{ABPD}, \tau, \max }$ & 7.2 \\
\hline $\mathrm{V}_{\mathrm{m}, \mathrm{K}-\mathrm{ABPD}, \tau, \mathrm{mid}}$ & -28.3 & $\mathrm{~m}_{\mathrm{K}-\mathrm{ABPD}, \tau, \min }$ & 0.8 \\
\hline $\mathrm{m}_{\mathrm{KCa}-\mathrm{AB}, \mathrm{inf}, \alpha}$ & $1 / 4$ & $\mathrm{~m}_{\mathrm{KCa}-\mathrm{AB}, \mathrm{inf}, \max }$ & $\begin{array}{c}\text { CaConc/ } \\
(\mathrm{CaC} \text { onc }+30)\end{array}$ \\
\hline $\mathrm{V}_{\mathrm{m}, \mathrm{KCa}-\mathrm{AB}, \text { inf,mid }}$ & -51 & $\mathrm{~m}_{\mathrm{KCa}-\mathrm{AB}, \mathrm{inf}, \min }$ & 0 \\
\hline $\mathrm{m}_{\mathrm{KCa}} \mathrm{PD}$,inf, $\alpha$ & $1 / 8$ & $\mathrm{~m}_{\mathrm{KCa}-\mathrm{PD}, \text { inf,max }}$ & $\begin{array}{c}\mathrm{CaConc} / \\
(\mathrm{CaConc}+30)\end{array}$ \\
\hline $\mathrm{V}_{\mathrm{m}, \mathrm{KCa}-\mathrm{PD}, \text { inf,mid }}$ & -51 & $\mathrm{~m}_{\mathrm{KCa}-\mathrm{PD}, \mathrm{inf}, \mathrm{min}}$ & 0 \\
\hline $\mathrm{m}_{\mathrm{KCa}, \tau, \alpha}$ & $-1 / 22.7$ & $\mathrm{~m}_{\mathrm{KCa}, \tau, \max }$ & 90.3 \\
\hline $\mathrm{V}_{\mathrm{m}, \mathrm{KCa}, \tau, \mathrm{\tau} \text { mid }}$ & -46 & $\mathrm{~m}_{\mathrm{KCa}, \tau, \min }$ & 15.21 \\
\hline $\mathrm{m}_{\mathrm{A}-\mathrm{ABPD}, \mathrm{inf}, \alpha}$ & $1 / 8.7$ & $\mathrm{~m}_{\mathrm{A}-\mathrm{ABPD}, \text { inf, } \max }$ & 1 \\
\hline $\mathrm{V}_{\mathrm{m}, \mathrm{A}-\mathrm{ABPD}, \mathrm{inf} \text {,mid }}$ & -27 & $\mathrm{~m}_{\mathrm{A}-\mathrm{ABPD}, \mathrm{inf}, \mathrm{min}}$ & 0 \\
\hline $\mathrm{m}_{\mathrm{A}-\mathrm{ABPD}, \tau, \alpha}$ & $-1 / 15.2$ & $\mathrm{~m}_{\mathrm{A}-\mathrm{ABPD}, \tau, \max }$ & 11.6 \\
\hline $\mathrm{V}_{\mathrm{m}, \mathrm{A}-\mathrm{ABPD}, \tau, \mathrm{mid}}$ & -32.9 & $\mathrm{~m}_{\mathrm{A}-\mathrm{ABPD}, \tau, \min }$ & 1.2 \\
\hline $\mathrm{h}_{\mathrm{A}-\mathrm{ABPD}, \mathrm{inf}, \alpha}$ & $-1 / 4.9$ & $\mathrm{~h}_{\mathrm{A}-\mathrm{ABPD}, \text { inf, } \max }$ & 1 \\
\hline $\mathrm{V}_{\mathrm{h}, \mathrm{A}-\mathrm{ABPD} \text {,inf,mid }}$ & -56.9 & $\mathrm{~h}_{\mathrm{A}-\mathrm{ABPD}, \text { inf,min }}$ & 0 \\
\hline
\end{tabular}

\begin{tabular}{|l|c|l|c|}
\hline \multicolumn{1}{|c|}{ Param } & Value & Param & Value \\
\hline $\mathrm{h}_{\mathrm{A}-\mathrm{ABPD}, \tau, \alpha}$ & $-1 / 26.5$ & $\mathrm{~h}_{\mathrm{A}-\mathrm{ABPD}, \tau, \max }$ & 38.6 \\
\hline $\mathrm{V}_{\mathrm{h}, \mathrm{A}-\mathrm{ABPD}, \tau, \mathrm{mid}}$ & -38.9 & $\mathrm{~h}_{\mathrm{A}-\mathrm{ABPD}, \tau, \min }$ & 7.4 \\
\hline $\mathrm{m}_{\mathrm{P}-\mathrm{AB}, \text { inf, } \alpha}$ & $1 / 3.05$ & $\mathrm{~m}_{\mathrm{P}-\mathrm{AB}, \text { inf,max }}$ & 1 \\
\hline $\mathrm{V}_{\mathrm{m}, \mathrm{P}-\mathrm{AB}, \text { inf,mid }}$ & -12 & $\mathrm{~m}_{\mathrm{P}-\mathrm{AB}, \text { inf,min }}$ & 0 \\
\hline $\mathrm{m}_{\mathrm{P}-\mathrm{AB}, \tau, \alpha}$ & 0 & $\mathrm{~m}_{\mathrm{P}-\mathrm{AB}, \tau, \max }$ & 0.5 \\
\hline $\mathrm{V}_{\mathrm{m}, \mathrm{P}-\mathrm{AB}, \tau, \mathrm{mid}}$ & 0 & $\mathrm{~m}_{\mathrm{P}-\mathrm{AB}, \tau, \min }$ & 0.5 \\
\hline
\end{tabular}

\section{NORMAL, SiLENT, AND RESTORED ACTIVITY IN THE MODELLED PYLORIC NETWORK}

To model the normal activity of the STG we modified all conductance parameters of all neurons randomly to a small extent within the $80-120 \%$ of the set default parameters. We ran 200 simulations of the network in order to assess the robustness against small random variations of the parameters. We note that conductance parameters can vary in biological STG neurons to a considerable extent and in some cases many folds $[14,15]$. To analyse the simulations we ran each of them for 150,000 time steps and considered the last 100,000 time steps for the analysis in order to avoid the part of the simulation where the steady state behaviour of the model is not yet reached.

The analysis of the normal behaviour of the model using randomly varied parameters shows that the considered small variation of the conductance parameters does not interfere with normal functioning of the model. Across all simulations the triphasic rhythm was preserved and the LP, PY and PD phases of the rhythm fitted the expectations for a normal pyloric rhythm (see Fig. 2).

To model the impact of de-centralisation first we note that the lack of neuromodulation effectively leaves switched off a considerable part of calcium ion channels that would let out $\mathrm{Ca}^{2+}$ ions form the internal calcium stores of the cell. In addition to this any ionic currents directly induced by neuromodulators also stop. Thus, to simulate de-centralisation we set the conductances of ionic currents directly dependent on neuromodulation $\left(g_{P}\right)$ to zero and reduce the conductance of calcium currents considerably. We note that reducing $\mathrm{g}_{\mathrm{P}}$ to zero on its own does not lead in our model to ceasing of firing of the neurons (the tri-phasic rhythm is maintained), although naturally it alters to some extent the dynamics of the model neurons (see Fig. 3). We investigated the level of reduction of calcium conductances required to stop the activity of all neurons and we found that above $63.053 \%$ of their normal value at least some of the model neurons keep firing. It should be noted that even small reduction (e.g. to $93 \%$ of the normal value) of the calcium conductances has significant effect on the overall rhythm, i.e. first the LP neuron stops firing, then for further lower calcium conductance values the firing of the PD neurons get distorted, the final model neurons to cease firing being the PY neurons. So to simulate the de-centralisation we chose to reduce the calcium conductance values in all cells to $60 \%$ of their pre-de-centralisation value (i.e. slightly below the limit at which spiking disappears from all neurons). 


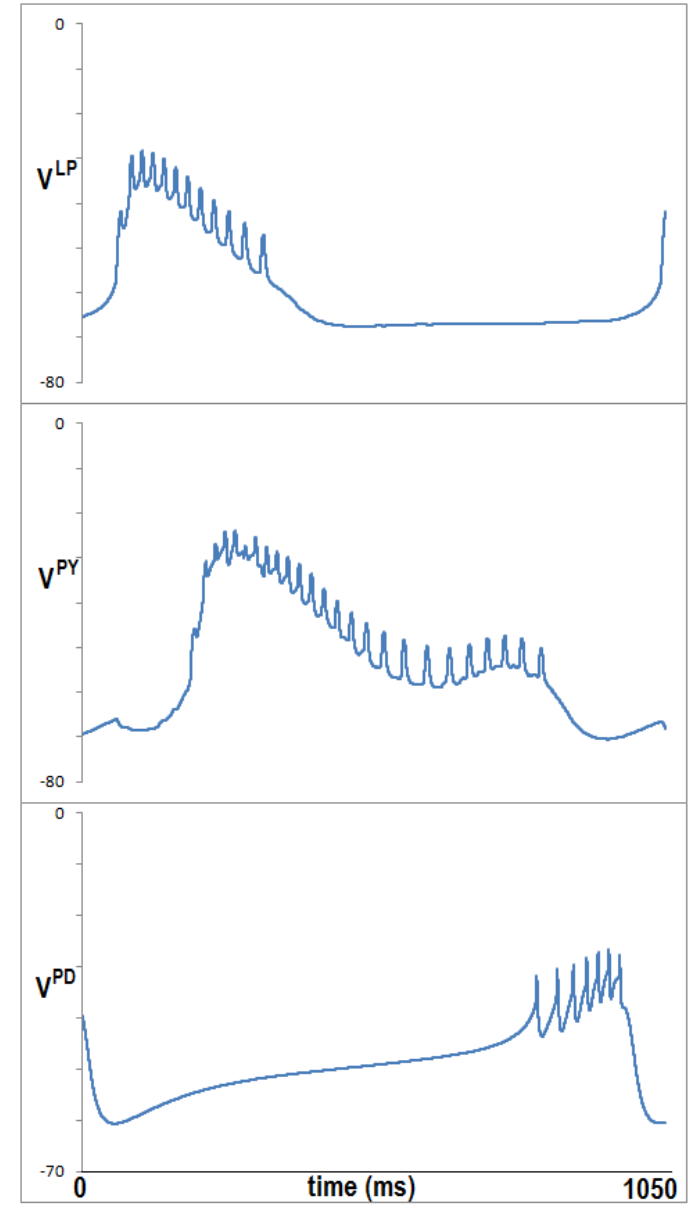

Fig. 2. The simulated normal activity of LP, PY and PD neurons (soma membrane potential differnece) showing the typical tri-phasic nature of the pyloric rhythm.

In the long term (hours) the impact of the loss of neuromodulation is the change of the transcription regulation of components of ion channel molecules. This leads to the relaxation of the correlation constraints between the levels of maximal conductances to which such constraints apply. In effect the values of maximal conductances of ionic currents may change considerably following de-centralisation. Our hypothesis is that sufficient changes in the maximal conductance values of ionic currents will restore the regular rhythmic activity of the pyloric network. We note that a similar approach applied to the potassium and calcium ion conductances have been considered before [6] and this relied on a specific mechanism of change of these conductances. However, we also note that there is no particular reason to assume that the calcium conductance would increase in the absence of neuromodulation.

First, we varied randomly the $g_{K}, g_{A}, g_{H}$ and $g_{N a P}$ conductances in a wide range $(10-1000 \%$ of the default values). The analysis of the resulting activity of the model STG shows that such randomly varied conductances cannot restore the activity of the model pyloric STG neurons. Next we varied in a narrow range $(80-120 \%)$ all these conductances and in addition varied much more $(250-550 \%)$ the $g_{N a P}$ conductance (present only in the model $\mathrm{AB}$ and $\mathrm{PD}$ neurons). This change restores the activity of at least one PD neuron in $22.5 \%$ of the cases and both PD neurons in $15 \%$ of the cases. It also restores the $\mathrm{AB}$ activity in $1 \%$ of the cases and the activity of all $\mathrm{PY}$
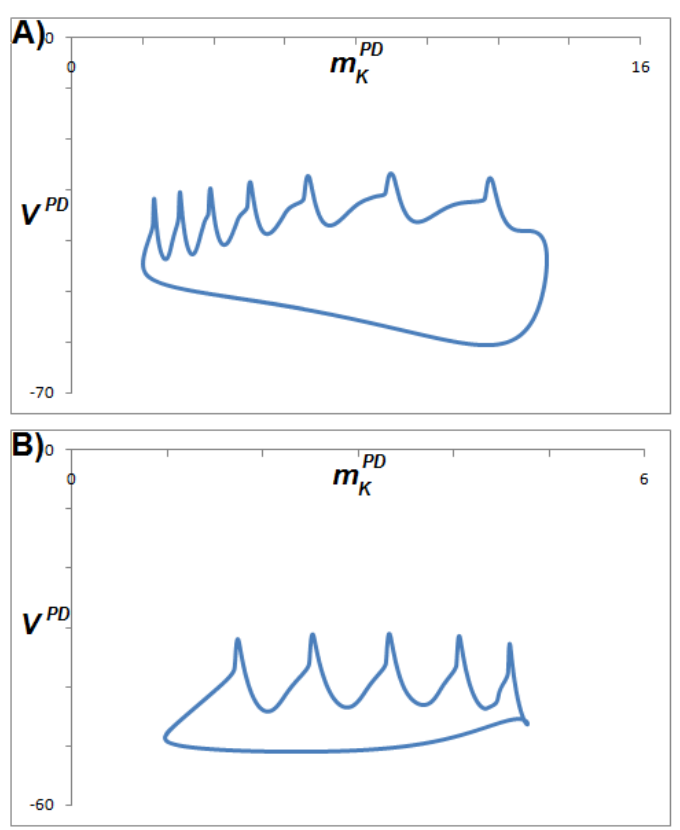

Fig. 3. Phase portrait of the activity of a simulated PD neuron with active neuromodulation induced currents (A) and without neuromodulation induced currents $(\mathrm{B})$ - note that these currents are active only in the simulated $\mathrm{AB}$ and LP neurons, both of which influence the acitvity of the PD neurons. The horizontal axis in both cases is the $m_{K}{ }^{P D}$ openness probability of potassium channels, and the vertical axis in both cases is the membrane potential difference $V^{P D}$ in the soma of the simulated neuron. Note that the value range of $m_{K}^{P D}$ is much narrower in the absence of neuromodulation induced currents.

neurons in $46 \%$ of the cases, but the LP neuron remained silent in all 200 simulation runs. Smaller scale variation (120$250 \%$ ) of the $g_{N a P}$ conductance is much less effective, resulting only in restoration of PY activity in $66 \%$ of the cases while all other neurons remain silent. Then we varied in the narrow range all noted conductances and varied much more $(250-$ $550 \%)$ the $g_{A}$ and $g_{H}$ conductances. This restored the LP activity in $35 \%$ of the cases and a variable number of PY neurons having all five PY active in 38\% of cases and at least one active in $96 \%$ of the cases, however neither the $\mathrm{AB}$ or the PD neurons were active. Smaller scale variation (120-250\%) of $g_{A}$ and $g_{H}$ conductances results in re-activation of all five PY neurons in $99.5 \%$ of the cases, but none of the other neurons return to spiking activity. Finally, we combined the variation of $g_{A}, g_{H}$ and $g_{N a P}$ conductances at larger scale $(250-550 \%)$, which resulted in the re-activation of one PD neuron $14.5 \%$ of the cases and of both PD neurons in 5.5\% of the cases, the LP neurons were active in $35.5 \%$ of the cases and the number of active PY neurons varied, all being active in $47 \%$ of the cases and at least one PY neuron being active in $99 \%$ of the 200 simulation runs, however the $\mathrm{AB}$ neuron remained silent in all runs. Modifying the same conductances to less extent (120$250 \%$ ) leaves silent all neurons with the exception of PY neurons which are active in $100 \%$ of the cases (200 simulation runs).

While the fully functional pyloric rhythm did not get restored (the $\mathrm{AB}$ activity was missing almost always) in the simulations implementing the de-regulation of conductances by random variation of these, the results show that the tri-phasic rhythm generated by the PD, LP and PY neurons was restored in $14.5 \%$ of the cases when we modified to larger extent ( $250-$ 
$550 \%)$ the $g_{A}, g_{H}$ and $g_{N a P}$ conductances. The above analysis shows that in the context of the model the PY activity gets relatively easily restored in any considered combination of conductance variations, however for the restoration of PD activity the sufficient large change of the $g_{N a P}$ conductance is required, and for the restoration of LP activity the sufficient large change the $g_{A}$ and $g_{H}$ conductances is required. The results also show that the variation of the $g_{K}$ conductance has to remain within relatively narrow limits in order to be able to restore the network activity in the simulated pyloric network.

\section{CONClusions}

The analysis of the simulated pyloric network of the crustacean STG presented here shows that restoration of the activity following de-centralisation can be achieved by letting some of the ionic current conductances $\left(g_{A}, g_{H}\right.$ and $\left.g_{N a P}\right)$ grow and vary to relatively large extent while keeping others $\left(g_{K}\right)$ in a relatively limited range. This approach does not require a relatively complex mechanism to modify the calcium and possibly potassium conductance of the neurons as it was proposed by earlier works [6-9].

Our simulation analysis shows that the presented model of the pyloric network is robust to smaller scale variation of the conductance parameters $(80-120 \%$ of the default values). It also shows that wide $(10-1000 \%)$ random variations of the conductance parameters are not compatible with the normal functioning of the model network. The analysis also highlights that the model is particularly sensitive to the variation of some conductance parameters $\left(g_{K}\right.$ and $\left.g_{C a}\right)$. At the same time in the context of our model the switching off of directly neuromodulator induced currents is insufficient to stop the pyloric rhythm, although alters the dynamics of the model neurons.

The work presented here is important for the understanding of how spontaneous functional restoration in small biological neural networks may emerge and how such functional restoration of activity may be triggered in more complex neural networks that do not have the spontaneous ability to regenerate their functional activity following disconnection from higher controlling neural centres. Our work suggests that sufficient relaxation of constraints and sufficient growth of conductances of some ionic currents may restore the spontaneous activity of neural systems. This may be achieved by deregulation and possibly enhancement of the transcription of genes corresponding to the required channel molecules.

Our future work aims to analyse the role of the parameters of inf and $\tau$ functions in the regulation of the activity of model neurons and of the model pyloric network. Changes to these parameters may provide the appropriate way of representing the impact of neuromodulators on ionic currents through the alteration of properties of the corresponding channel molecules. Better understanding of how to model the impact of neuromodulation will help to capture better the effect of the presence and absence of neuromodulators and is expected to also help in better modelling of functional restoration of the pyloric network by incorporating possible impacts of neuromodulators (e.g. would the short term presence of particular neuromodulators facilitate the functional restoration process).

\section{REFERENCES}

[1] R.M. Harris-Warrick, E. Marder, A.I. Selverston and M. Moulins (eds.), The Stomatogastric Nervous System: A Model Biological Neural Network, MIT Press, 1992.

[2] Ö. Ekeberg, P. Wallén, A. Lansner, H. Trávén, L. Brodin, S. Grillner, "A computer based model for realistic simulations of neural networks. I. The single neuron and synaptic interaction", Biological Cybernetics, vol. 65, pp. 81-90, 1991.

[3] L.F. Abbott and T.B. Kepler, "Model neurons: from Hodgkin-Huxley to Hopfield", L. Garrido (ed.), Statistical Mechanics of Neural Networks, Springer, pp. 5-18., 1990.

[4] E.M. Izhikevich, Dynamical Systems in Neuroscience, MIT Press, 2007.

[5] M.A. Lebedev and M.A.L. Nicolelis, "Brain -machine interfaces: past, present and future", Trends in Neurosciences, vol.29, pp.536-546, 2006.

[6] J. Golowasch, M. Casey, L.F. Abbott, E. Marder, "Network stability from activity-dependent regulation of neuronal conductances", Neural Computation, vol.11, pp.1079-1096, 1999.

[7] Y. Zhang and J. Golowasch, "Modeling recovery of rhythmic activity: hypothesis for the role of a calcium pump", Neurocomputing, vol.70, pp.1657-1662, 2007.

[8] Y. Zhang, O. Khorkova, R. Rodriguez, J. Golowasch, "Activity and neuromodulatory input contribute to the recovery of rhythmic output after decentralization in a central pattern generator", Journal of Neurophysiology, vol.101, pp.372-386, 2009.

[9] Y. Zhang and J. Golowasch, "Recovery of rhythmic activity in a central pattern generator: analysis of the role of neuromodulator and activitydependent mechanisms", Journal of Computational Neuroscience, vol.31, pp.685-699, 2011.

[10] C. Soto-Trevinño, P. Rabbah, E. Marder, F. Nadim, "Computational model of electrically coupled, intrinsically distinct, pacemaker neurons", Journal of Neurophysiology, vol.94, pp.590-604, 2005.

[11] A.A. Prinz, C.P. Billimoria, E. Marder, "Alternative to hand-tuning conducatance-based models: construction and analysis of databases of model neurons", Journal of Neurophysiology, vol.90, pp.3998-4015, 2003.

[12] T. Nowotny, A. Szücs, R. Levi, A.I. Selverston, "Models wagging the dog: Are circuits constructed with disparate parameters?" Neural Computation, vol.19, pp.1985-2003, 2007.

[13] O. Khorkova, J. Golowasch, "Neuromodulators, not activity, control coordinated expression of ionic currents", Journal of Neuroscience, vol.27, pp.8709-8718, 2007.

[14] D. Bucher, A.A. Prinz, E. Marder, "Animal-to-animal variability in motor pattern production in adults and during growth", Journal of Neuroscience, vol.25, pp.1611-1619, 2005.

[15] S. Temporal, M. Desai, O. Khorkova, G. Varghese, A. Dai, D.J. Schulz, J. Golowasch, "Neuromodulation independently determines correlated channel expression and conductance levels in motor neurons of the stomatogastric ganglion", Journal of Neurophysiology, vol.107, pp.718727, 2012. 